\title{
POETRY
}

\section{Pronouncing death 2}

I have practised these words the motions of this form, watched for the rise and fall of a chest,

listened for a heart expecting it gone. At nursing stations I have written names last, first, middle checked boxes declared antecedent causes signed.

Still here I was arrested alongside your stranger bed by octogenarian nails painted fire-engine red. Nobody left to explain the story.

I too have left you alone in a room with motes of retinal light.

Stepping around puddles in the driving rain, recalling infants prefer to sleep with something touching their head.

\section{Kevin Bezanson MD}

Family physician

Temmy Latner Centre for Palliative Care Mount Sinai Hospital

Toronto, Ont.

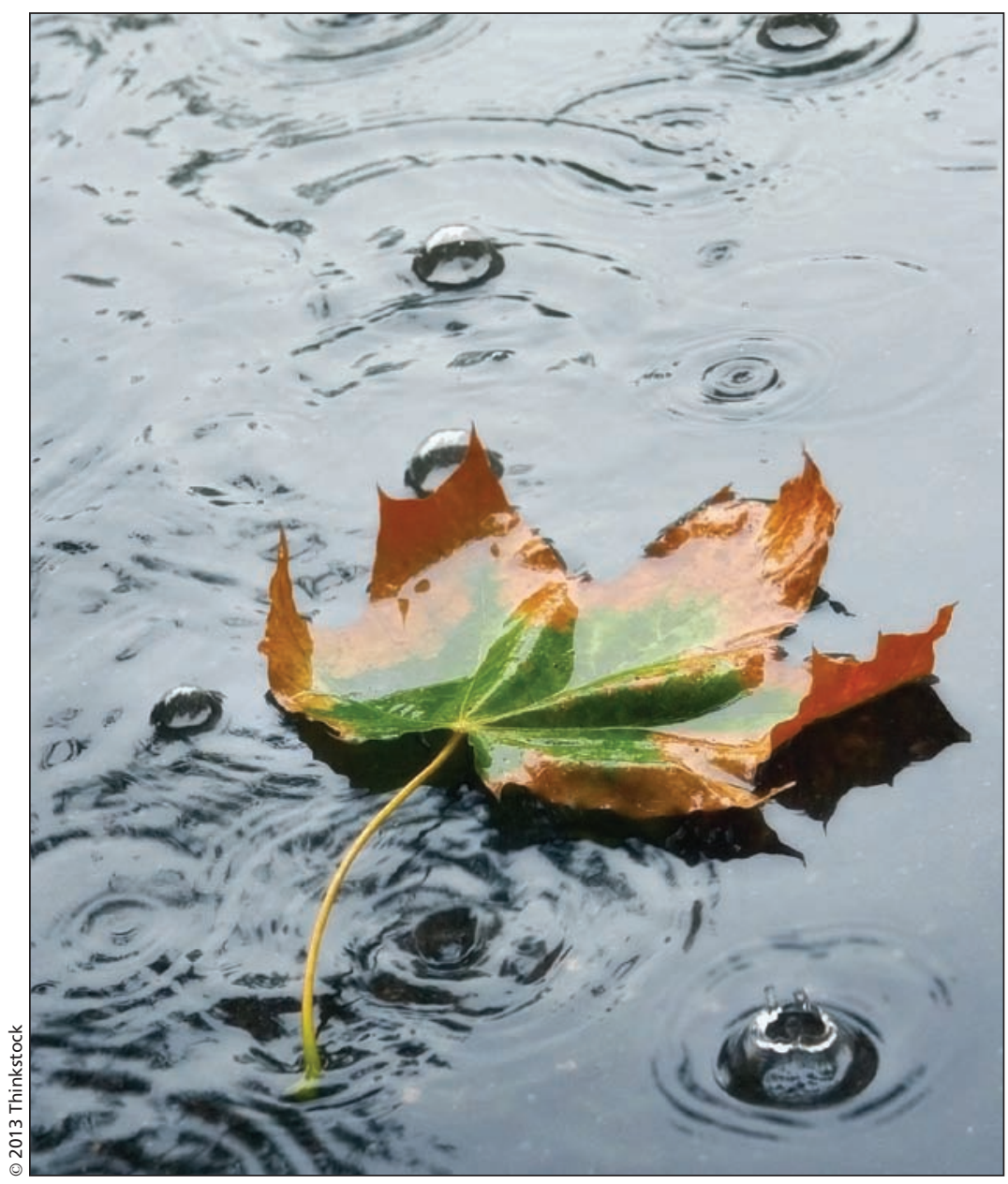

CMAJ 2013. DOI:10.1503/cmaj.121901 